\title{
Mechanism of Coal Bump among Mine Group under the Control of Large Geological Body: A Case Study of Yima Mining Area, China
}

\author{
Yizhe Li, ${ }^{1,2,3}$ Shankun Zhao ${ }^{(D)},{ }^{2,3}$ Qingxin Qi, ${ }^{3,4}$ Pengzhi Pan, ${ }^{5}$ Xiangzhi Wei, ${ }^{6}$ Yin Wang, ${ }^{2,4,7}$ \\ Ningbo Zhang, ${ }^{2,4}$ Yang Zhao, ${ }^{2,4}$ Haitao Chai, ${ }^{2,4}$ and Qilin Hao ${ }^{6}$ \\ ${ }^{1}$ China Coal Research Institute, Beijing 100013, China \\ ${ }^{2}$ Mine Safety Technology Branch, China Coal Research Institute, Beijing 100013, China \\ ${ }^{3}$ State Key Laboratory of Coal Mining and Clean Utilization, Beijing 100013, China \\ ${ }^{4}$ Deep Mining and Rockburst Research Institute, China Academy of Coal Science, Beijing 100013, China \\ ${ }^{5}$ State Key Laboratory of Geomechanics and Geotechnical Engineering, Institute of Rock and Soil Mechanics, \\ Chinese Academy of Sciences, Wuhan, Hubei 430071, China \\ ${ }^{6}$ Henan Da You Energy Co., Ltd., Yima 472300, China \\ ${ }^{7}$ School of Resources Safety Engineering, China University of Mining and Technology (Beijing), Beijing 100083, China
}

Correspondence should be addressed to Shankun Zhao; zhaoshankuncom@163.com

Received 10 August 2020; Accepted 24 June 2021; Published 8 July 2021

Academic Editor: Dawei Yin

Copyright ( $\odot 2021$ Yizhe Li et al. This is an open access article distributed under the Creative Commons Attribution License, which permits unrestricted use, distribution, and reproduction in any medium, provided the original work is properly cited.

Coal bump often occurs in coal mining among many working faces in mine group under the control of large geological bodies. In order to study the coal bump mechanism between adjacent working faces under the conditions of large fault and huge thick overburden conglomerate, this paper regards Yima mining area as a practical engineering background and theoretically analyzes the mechanical behavior of overlying rock in the spatial structure. Then, the deep-ground and whole-space measurement is carried out in the 13230 working face of Gengcun mine and 21121 working face of Qianqiu mine. The results show that the basic structural unit in Yima mining area is composed of two goafs, middle coal pillar, and overlying conglomerate. Under the condition of nonsynchronous mining in adjacent working faces, there is a comovement effect similar to lever's "prying" phenomenon in thick conglomerate beam - the conglomerate strata above larger goaf side induce an overall uplift movement of the corresponding strata above smaller goaf side, and uplift length of the conglomerate strata is related to the mining length, coal pillar width, caving angle, and coal-conglomerate distance. The results of surface subsidence, microseism, and stress in the two working faces verify the conglomerate's phenomenon of comovement effect and disturbance range and further explain the role of active movement of F16 fault and overall causes of huge thick conglomerate on the coal bump. The vertical stress of the 13230 face is relatively low at the beginning, and high horizontal stress by fault activation causes typical bump accident with the horizontal sliding of coal body. With the increasing development of 13230 face, the intensity and frequency of coal bump in horizontal direction decrease obviously, but with high proportion in vertical direction. The results provide a theoretical basis for the study on the mechanism of coal bump between two adjacent working faces under the conditions of huge thick conglomerate and large thrust fault.

\section{Introduction}

The strata's behaviors above working face in the coal mine are closely related to the structural characteristics and movement law of overburden rock. When the adjacent working faces are mined at the same time, they will also be affected by each other, especially under the condition of large fault or huge thick conglomerate roof. If the mining of one face causes fault activation or movement of huge thick conglomerate stratum, it will affect the adjacent working face.

In this way, such a large geological body will lead to a larger scale and severer degree of stress disturbance and highly increase the risk of coal and rock dynamic disaster $[1,2]$.

At present, scholars at home and abroad have studied the influence of overburden structure classification, moving law, 
failure mode, and stress distribution on the coal bump. Structures in shallow mining and deep mining with extrathick and steep-inclined coal seam are, respectively, stress arch and articulated rock beam. Linming Dou [3] thought that integrated spatial structure of overlying strata is composed of "O-X," "F," and "T," which causes abnormal stress concentration. For caving coal mining, some scholars have studied the movement law of overlying rock structure under caving coal mining [4-7] and proposed reducing the top coal loss with changing roof structure $[8,9]$.

For the evolution of overburden structure, there is a great difference in breaking mode with near field and far field [10-12], and in strata behavior of working face and goaf roadway with different thickness, strength, and height of key roof strata $[13,14]$. High strength of direct roof mediumthick strata, large thickness, and low strata lead to high roof pressure $[15,16]$. On the other hand, the instability of the overlying structure usually produces large vibration energy [17-19], which produces high dynamic and static load [20-22] to the working face and easily induces coal and rock dynamic disasters.

At present, the research on the mining disturbance law mostly focuses on the scale of single working face, while the research on the disaster caused by large-scale movement of overlying rock structure under the scale of mining area is not much. In this paper, Yima mining area is taken as the research object for its frequent coal bump, and the mechanical behavior of structural unit in largescale mining area is analyzed theoretically. Taking the adjacent working face as an example-13230 working face of Gengcun coal mine and 21121 working face of Qianqiu coal mine-based on the monitoring of microseism, stress, surface subsidence, and dynamic behavior, this paper proposes the process of disaster caused by disturbance of F16 fault and huge thick conglomerate, which provides theoretical basis for the study of the mechanism of coal bump in adjacent working face under the condition of Mining Group.

\section{Engineering Background}

2.1. Characteristics of Large Geological Bodies in Yima Mining Area. Yima mining area is a typical coal bump prone area in China. It is located in Yima City, Henan Province, China. Five mines are distributed from West to East: Yangcun coal mine, Gengcun Coal Mine, Qianqiu Coal Mine, Yuejin Coal Mine, and Changcun coal mine. After decades of mining, the depth has been close to $900 \mathrm{~m}$. The thickness of conglomerate close to Earth's surface above deep mining area is $300 \sim 700 \mathrm{~m}$, and there is a large thrust fault named F16 in the southern minefield boundary, which controls five coal mines. Therefore, coal bump has become one of the main disasters in Yima mining area. The geographical location, current state of mining, and tectonic distribution of the Yima mining area are shown in Figure 1.

The basic characteristics of the huge thick conglomerate and F16 fault are as follows:
2.1.1. Huge Thick Conglomerate. The stratum develops in the whole coalfield, and its thickness gradually increases from North to South, from the Eastern and Western boundary to the central southern areas. Especially in the South of Yuejin minefield, the thickness is largest for more than $700 \mathrm{~m}$. The thickness contour is shown in Figure 2. The huge thick conglomerate has high strength and strong integrity, so it is likely that a large-scale movement will occur in the extremely thick stratum with gradual mining, and the influence's range may exceed a single working face, which may disturb the stress environment of other mine working faces and induce coal bump.

2.1.2. F16 Fault. The fault's strike is nearly from northwest to southeast. According to the geological borehole section (Figure $1 \mathrm{~A}-\mathrm{A}^{\prime}$ ) at the boundary of Gengcun and Qianqiu Coal Mine, the fracture surface of F16 is plough-shaped with steep top and gentle bottom, and the dip angle in shallow area is larger but gradually flat in the deep part. According to the core from borehole and F16 outcropping on the surface, it can be seen that the compression force of F16 fault causes large-scale thrusting and sliding northward along the top surface. The activation movement makes the working face in such an environment with high horizontal stress and increases the probability of coal bump in the working face and roadway. The morphology of F16 fault is shown in Figure 3 [23].

2.2. Structural Characteristics of Mine Group. From the current layout and mining design of Yima mining area, it can be seen that, in the east-west direction, there are different types of coal pillars, such as the adjacent mines in a coalfield, the adjacent district in a mine, and the adjacent wings in a district, with the widths of 140 200 m, 50 100 m, and $150 \sim 300 \mathrm{~m}$, respectively. With the large-scale mining in the area, a large number of "goaf-pillar- goaf" structures have been formed. As the basic unit of large-scale structure, it should be the primary research object for structural disturbance issue.

In order to understand the roof falling morphology of adjacent working face in structural unit, 13230 face in Gengcun mine and 21121 face in Qianqiu mine at both boundaries of two mines are selected as an engineering object (Figure 2). The location of the two faces is shown in Figure 2. Surface drilling was carried out above goaf in 21121 face (Figure 4) to detect the development of three zones.

From bottom to top, there are siltstone over $180 \mathrm{~m}$, $6.17 \mathrm{~m}$ mudstone, $23.4 \mathrm{~m}$ coal seam, $29.51 \mathrm{~m}$ mudstone, $217.6 \mathrm{~m}$ interbed of sandstone and conglomerate, and $401.55 \mathrm{~m}$ huge thick conglomerate, respectively. According to the integrity of the drilled core and the phenomena of slurry leakage, water outflow, drilling drop, and gas emission during drilling, the three zones of overburden rock during two face's mining are shown in Figure 4. The thick conglomerate is nonobvious large fracture overall, which locally collapses at $120 \mathrm{~m}$ below (290-410 $\mathrm{m}$ in Figure 4), but the integrity of the upper part is good $(20-290 \mathrm{~m})$, which is bending zone. 


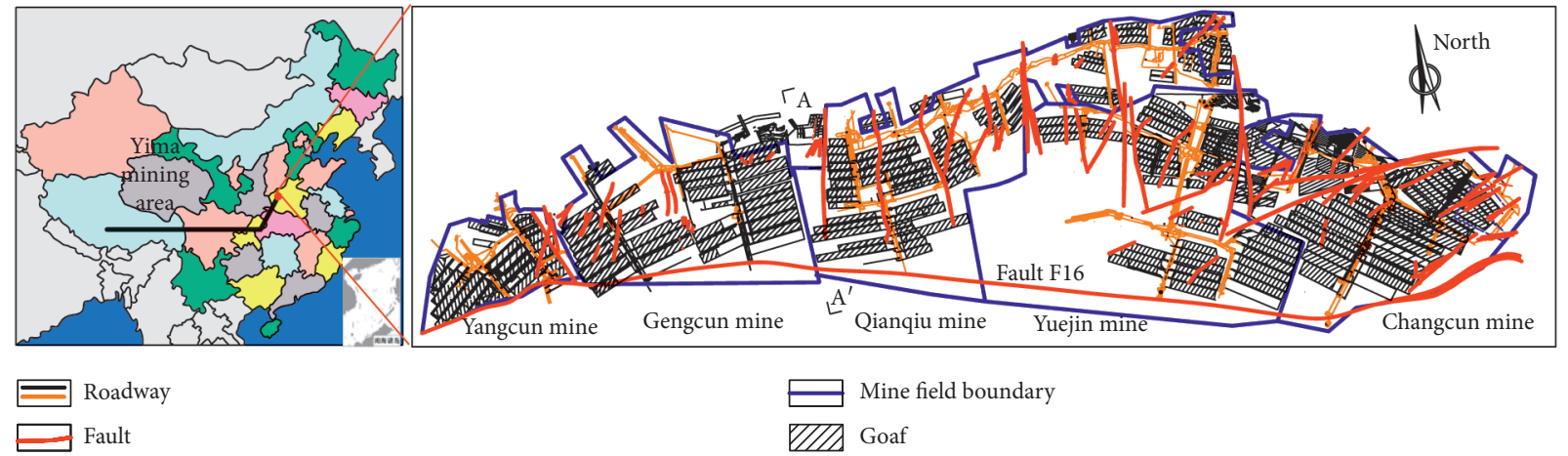

FIgURE 1: The geographical location, current state of mining, and tectonic distribution of the Yima mining area.

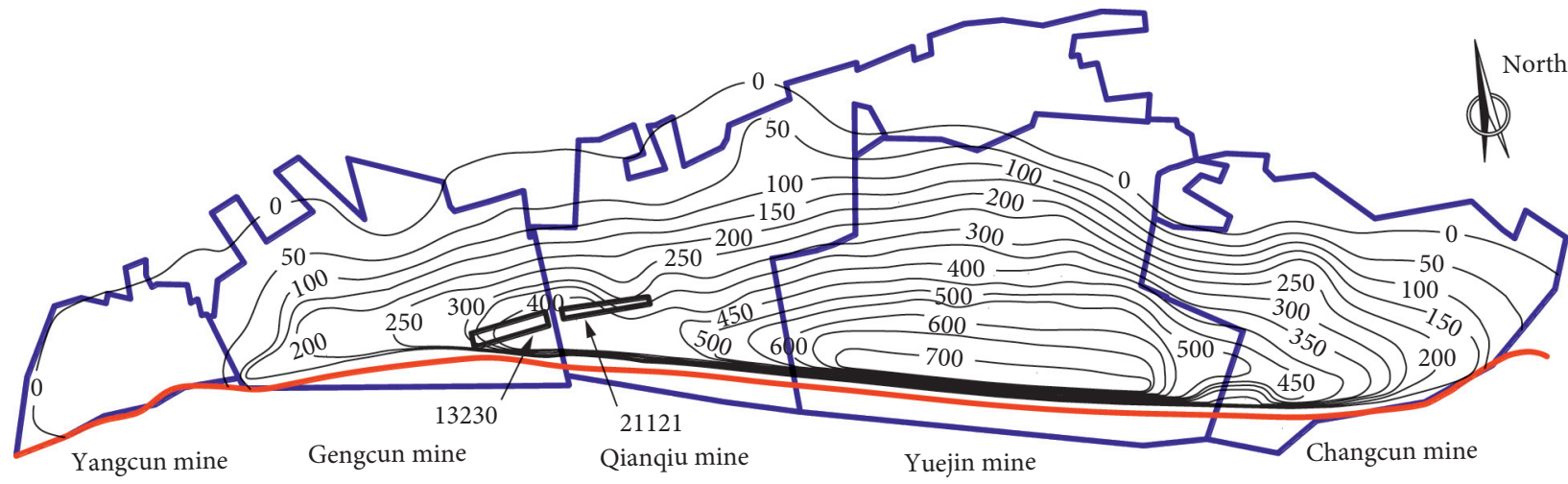

\footnotetext{
$\longrightarrow$ Mine field boundary

Fault F16

$-100-$ Thickness contour of conglomerate
}

FIgURE 2: Thickness distribution of conglomerate in Yima mining area.

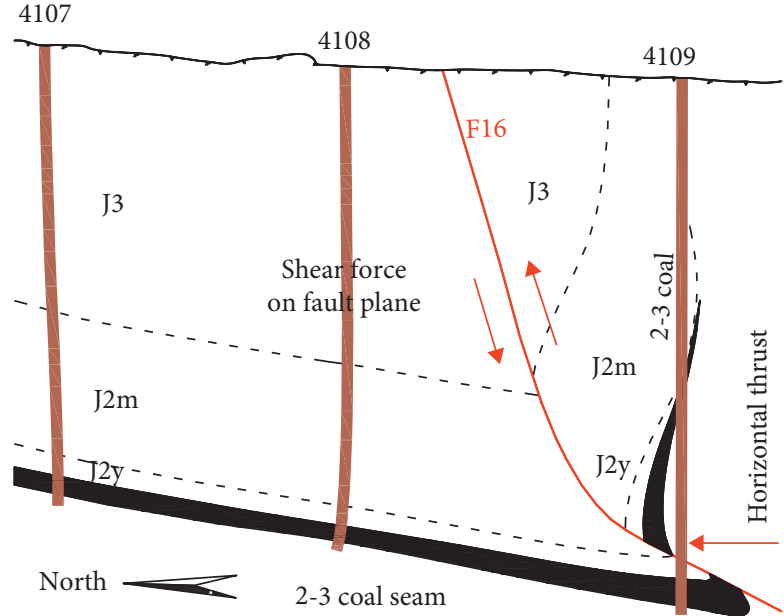

Figure 3: The morphology of faultF16 in A-A' section [23]. 

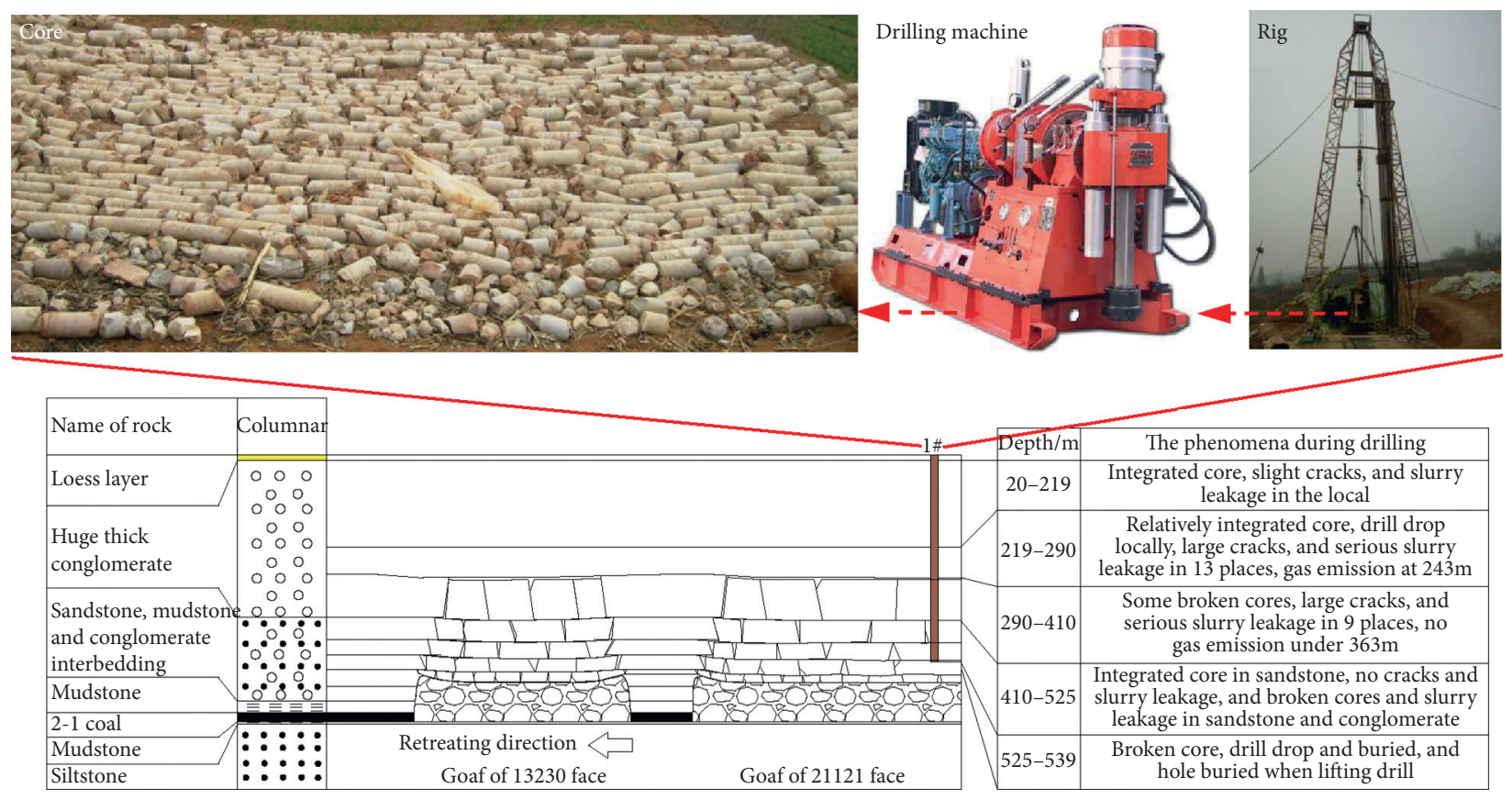

FIGURE 4: Spatial structure of overburden strata between 13230 and 21121 goafs.

\section{Theoretical Analysis of Comovement Behavior of Thick Conglomerate}

3.1. Mechanical Model and Boundary Conditions. The huge thick conglomerate in the structural unit is stratified (Figure 4). As for the spatial structure, the strata directly controlling the adjacent working faces are $71 \mathrm{~m}$ conglomerate (219-290 $\mathrm{m}$ in Figure 4) in the low positions of the bending zone, so it is taken as the research object. When the mining length of the two faces is quite long, the hanging length of the conglomerate is far greater than its thickness $(71 \mathrm{~m})$, so it can be simplified as a beam model to solve. In order to facilitate calculation and analysis, the thin layer (Figure 5(a)) is set as the state of fixed support at both ends and hinge support in the middle, and the stress state is shown in Figure 5(b).

In this model, $a$ and $b$ are, respectively, the distance from the hanging boundary of two faces to the coal pillar center, not the real hanging length of the two thin layers $-a$ ' and $b^{\prime}$. In order to facilitate the description, $a$ and $b$ in the model are called hanging lengths of the rock beam above the two working faces because $a, b$ and the real hanging length are proportional, and $a^{\prime}, b^{\prime}$ are not involved in the later calculation. In addition, the working faces with longer goaf and shorter goaf are called former face and later face, respectively.

The fracture of overlying strata develops upwards according to a certain angle, so in order to correctly solve the hanging size of thin layer, the influence of caving angle $\alpha$, distance from coal seam to thin layer $h$, and coal pillar width $J$ should be considered. Then, the relationships between $a, b$ and the length of goaf $m, n$ in the simplified model are as follows:

$$
\begin{aligned}
& a=m+\frac{J}{2}-h \cot \alpha, \\
& b=n+\frac{J}{2}-h \cot \alpha .
\end{aligned}
$$

According to the material mechanics, With uniformly distributed load at the upper surface and fixed at two ends, the expressions of shear force and deflection [24] on arbitrary section of rock beam are as follows:

$$
\begin{aligned}
& F_{1}(x)=\frac{q l}{2}-q x \\
& \omega_{1}(x)=-\frac{1}{\mathrm{EI}}\left(-\frac{1}{24} q x^{4}+\frac{1}{12} q l x^{3}-\frac{1}{24} q l^{2} x^{2}\right) .
\end{aligned}
$$

In the above formula, $x=0$ is located at point $A$ of the beam, and the direction of $x$ axis is from point A to point B. The coordinate system in this paper is consistent.

With concentrated force in the middle and fixed at two ends, the expressions of shear force and deflection [24] are as follows: 


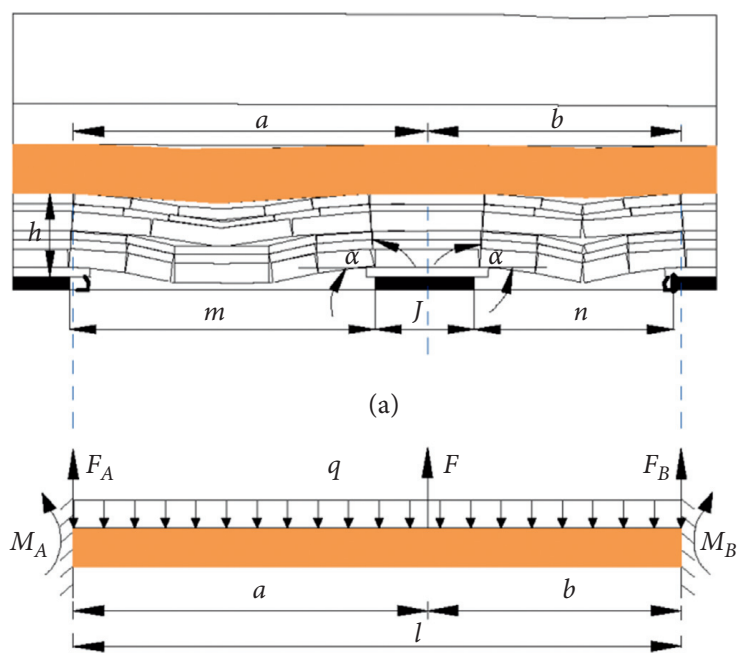

(b)

Figure 5: Mechanical model and boundary condition of the structural unit: (a) spatial structure of overlying strata and (b) simplified mechanical model.

$$
\begin{aligned}
& F_{2}(x)= \begin{cases}-\frac{F b^{2}}{l^{2}}\left(1+\frac{2 a}{l}\right), & 0 \leq x<a, \\
\frac{F a^{2}}{l^{2}}\left(1+\frac{2 b}{l}\right), & a<x \leq l,\end{cases} \\
& \omega_{2}(x)= \begin{cases}-\frac{F b^{2}}{6 \mathrm{EI}}\left(-\frac{3 a+b}{l^{3}} x^{3}+\frac{3 a}{l^{2}} x^{2}\right), & 0 \leq x \leq a, \\
-\frac{F a^{2}}{6 \mathrm{EI}}\left[\frac{a+3 b}{l^{3}} x^{3}-\frac{3 a+6 b}{l^{2}} x^{2}+3 x-a\right], & a \leq x \leq l .\end{cases}
\end{aligned}
$$

The deflection [23] of spot $\mathrm{C}$ of rock beam under the two load conditions is as follows:

$$
\begin{aligned}
& \omega_{C 1}=\frac{q a^{2} b^{2}}{24 \mathrm{EI}}, \\
& \omega_{C 2}=-\frac{F}{3 \mathrm{EI}} \times \frac{a^{3} b^{3}}{(a+b)^{3}} .
\end{aligned}
$$

According to the superposition principle of material mechanics, under the two load conditions, the expressions of shear force and deflection on arbitrary section of rock beam are equal to superposition of physical quantity under their respective conditions, and the expression of shear force $(F)$ is as follows:

$$
F(x)=F_{1}(x)+F_{2}(x) .
$$

The reaction forces $F_{A}$ and $F_{B}$ of the coal-rock mass supporting rock beam and deflection of point $C$ in the coal pillar are, respectively, as follows:

$$
\begin{aligned}
& F_{A}=F(x=0)=\frac{q l}{2}-\frac{F b^{2}}{l^{2}}\left(1+\frac{2 a}{l}\right), \\
& F_{B}=-F(x=l)=\frac{q l}{2}-\frac{F a^{2}}{l^{2}}\left(1+\frac{2 b}{l}\right), \\
& \omega_{C}=\frac{q a^{2} b^{2}}{24 \mathrm{EI}}-\frac{F}{3 \mathrm{EI}} \times \frac{a^{3} b^{3}}{(a+b)^{3}} .
\end{aligned}
$$

Considering the coal pillar and upper overlying rock pillar as a rigid body, the deflection of point $C$ is 0 , that is, $\omega_{C}=0$. So, the supporting force of the coal pillar to conglomerate beam can be obtained by the following expression:

$$
F=\frac{q l^{3}}{8 a b} .
$$

Putting equation (12) into equations (9) and (10), it can be concluded that the reaction forces $F_{\mathrm{A}}$ and $F_{B}$ are as follows:

$$
\begin{aligned}
& F_{A}=\frac{q l}{2}-\frac{q l b}{8 a}\left(1+\frac{2 a}{l}\right), \\
& F_{B}=\frac{q l}{2}-\frac{q l a}{8 b}\left(1+\frac{2 b}{l}\right) .
\end{aligned}
$$

Putting equation (12) into equations (4) and (6) and superimposing the two formulas, the deflection equation on 
arbitrary section of rock beam can be obtained by the following expression:

$$
\omega(x)= \begin{cases}\frac{q}{24 \mathrm{EI}} x^{2}(x-a)\left[x-\frac{l(2 a-b)}{2 a}\right], & 0 \leq x \leq a, \\ \frac{q}{24 \mathrm{EI}}(x-a)(x-l)^{2}\left(x-\frac{a l}{2 b}\right), & a \leq x \leq l .\end{cases}
$$

\subsection{Comovement Characteristics of Conglomerate Beam}

3.2.1. Comovement Form. As for the formula (14), the corresponding range of the conglomerate beam above the later face is $a \leq x \leq l$, and the four roots of $\omega(x)=0$ are $x_{1}=a, x_{2}=x_{3}=l, x_{4}=a l / 2 b$ respectively. Thus, there is $x_{4}-x_{3}=l(a-2 b) / 2 b$.

(1) Early Mining of Later Face. In this period, the hanging length of rock beam above the later face is far less than that of the former face; that is, when $a>2 b$, then $x_{4}>x_{3}$. According to the positive and negative results of the polynomial, it can be seen that $\omega(x)<0$ is always established on $a \leq x \leq l$. So the state of rock beam above later face is bending and uplifting.

(2) Middle and Later Mining Stage of Later Face. When the mining length of the later face is quite long, the value of $2 b-a$ changes from negative to positive; that is, when $a<2 b$, then $x_{4}<x_{3}$. According to the judgment, the value of $\omega(x)$ is negative and positive in the interval $[a, a l / 2 b]$ and $[a l / 2 b, l]$. So the state of later-face rock beam in the two intervals is uplifting and sinking, respectively.

The form evolution of conglomerate beam in the mining process of two working faces is shown in Figure 6.

3.2.2. Disturbance Range Based on Comovement Form. It is considered that the conglomerate has a strong disturbance on the later face when the whole rock beam is in uplifting state. At this time, the hanging lengths of conglomerate beam in two working faces meet the following relationship:

$$
b \leq \frac{a}{2} .
$$

Putting equations (1) and (2) into equations (6) and (15), the following relationship can be obtained:

$$
n \leq \frac{m}{2}-\frac{J}{4}+\frac{h \cot \alpha}{2}
$$

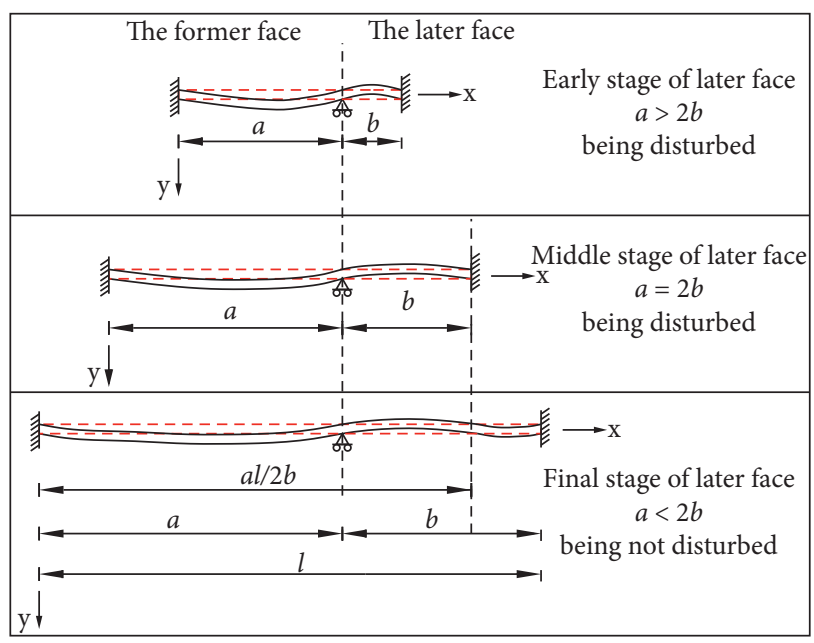

FIGURE 6: The change of conglomerate's form in the process of two mining faces.

Therefore, when the mining lengths of the two working faces meet the relationship of equation (16), the later face will be disturbed by the uplifting of rock strata.

\section{Field Test of Structure-Induced Coal Bump under the Control of Large Geological Body}

\subsection{Integrated and United Monitoring with Deep-Ground and Whole-Space}

4.1.1. Overview of Monitoring Area. Considering the current mining situation of each coal mine, Gengcun Mine and Qianqiu Mine have close adjacent working faces (13230 face and 21121 face), and the two working faces have occurred many times with severe coal bumps during their mining, so the targeted research on the two faces area is carried out. The strike length and inclined length of 13230 working face are $971 \mathrm{~m}$ and $196 \mathrm{~m}$, respectively. The north side of 13230 face is 13210 goaf and the south and west sides are unexploited coal mass. In the East, it is adjacent to 21121 face of Qianqiu coal mine. The coal pillar at the boundary of the two-mine area is $160 \mathrm{~m}$. The strike length and inclined length of 21121 working face are $1220 \mathrm{~m}$ and $130 \mathrm{~m}$, respectively, and its north and south sides are both goafs.

13230 started mining from 2015-12-1, then stopped for one year after coal bump accident on 2015-12-22, and resumed on 2016-11-1. It is now in production and is expected to be completed on 2020-10-1. 21121 face and the two in the north and south were stopped in 2007, 2012, and 2009, respectively. 
The two faces used retreating method, and the mining direction is from mine-boundary pillar to the terminal mining line. The mining length per day of two faces is all $0.8 \mathrm{~m}$. The working face distribution and mining state in this area are shown in Figure 7.

4.1.2. Monitoring Arrangement. In order to understand the movement behavior of huge thick conglomerate and F16 fault and their influence on the two working faces, the integrated and whole-space monitoring of dynamic response in coal and rock mass is carried out in the two faces. The following measures are used in 13230 face: (1) two lines with leveling observation are set up along the strike and dip orientation on the ground above 13230, and then 5 and 28 points are arranged, respectively, numbered 50\# 54\# and 21\# 34\#. (2) The online monitoring system for roof is installed on the hydraulic supports to monitor the roof pressure continuously for 24 hours. (3) The ARAMIS microseismic system is used to continuously monitor the microseismic activities of coal and rock mass. In 21121 face, the ARAMIS microseismic monitoring system is used to continuously monitor the goafs. All the monitoring points are shown in Figure 7.

4.2. Comovement Characteristics of Huge Thick Conglomerate. According to the monitoring data of surface subsidence and microseismic event from 4.1.2, the comovement effect of huge thick conglomerate in the model is explained. The monitoring data are as follows.

4.2.1. Analysis of Surface Subsidence. The surface subsidence along the strike of 13230 face from December 1, 2016, to August 1, 2019, is shown in Figure 8 [23]. It can be seen that surface subsides overall, but some points have "sudden jump" phenomena in the adjacent monitoring period.

In the early mining, many points on surface uplift in many periods, such as rising 3 40 $\mathrm{mm}$ of $51 \sim 53 \#$ on July 1 2018, rising 3 59 mm of 51\# and 53 54\# on August 1 2018, and rising $2 \sim 26 \mathrm{~mm}$ of $50 \#$ and $52 \sim 54 \#$ on September 1 2018.

In the middle time, the number of rising points and the rising's extent on the surface reduce significantly, such as rising $9 \mathrm{~mm}$ and $6 \mathrm{~mm}$ of 50\# and 53\# on December 12018 , rising $27 \mathrm{~mm}$ of 53\# on January 12019 , rising $26 \mathrm{~mm}$ of 52\# on March 1 2019, rising $59 \mathrm{~mm}$ of 50\# on April 1 2019, and rising $3 \mathrm{~mm}$ of 53\# on June 12019.

In the last stage, each point on the surface will not rise any more.

4.2.2. Analysis of Microseismic Height. Limited by the spatial arrangement, parameter setting, and monitoring ability, the microseismic equipment can only monitor the movement of rock mass within a certain range, but cannot reflect that in higher strata. As for the microseismic height in 13230 face, the highest and the lowest are $268 \mathrm{~m}$ and $-82 \mathrm{~m}$, respectively, and the height of 0 indicates the floor. It can be seen from Figure 4 that the distance from the lower hanging strata to the coal seam is $358.66 \mathrm{~m}$, which indicates that the microseismic system cannot monitor the movement of the hanging conglomerate. Coal and soft mudstone (direct roof and direct floor) are broken more severely, due to the "pressurization" of strata's subsidence, resulting in a lower position of microseismic events; on the contrary, the uplifting of the conglomerate leads to an increasing proportion of the higher strata's activity, resulting in a higher position of microseismic events. Therefore, the height of microseismic events can be used to indirectly characterize the movement law of high-level strata. In order to express the space-time evolution of the hanging stratum more intuitively, Figure 9 shows the average height of monthly microseismic events in 13230 face and Qianqiu 21 mining area from November 1, 2015, to May 21, 2019. In addition, since microseismic equipment was not used to monitor 21121 face while being used in 21141, therefore, the average height of monthly microseismic events in 21141 face from April 1, 2010, to October 1, 2012, is also shown in Figure 9 [23].

It can be seen from Figure 9 that there is a sudden increase of microseismic height in several months at the early and middle stages. In the last stage, with the structural balance, there is no larger sudden increase phenomenon, and more microseismic events occur in the coal mass with a height of $0-10 \mathrm{~m}$.

As for the height of microseismic events in Qianqiu 21 mining area, it is lower than 13230 face before 2019-10 and higher than that afterwards overall. It is consistent with the uplift state of conglomerate in the early and middle stage and the subsidence state in last stage.

For the only mining of 21141 face earlier, the monthly microseismic events fluctuate within $-40 \sim 130 \mathrm{~m}$. The height is significantly lower than that of 13230 face and Qianqiu 21 mining area, which also confirms the direction of comovement.

\subsubsection{The Disturbance Range of Comovement of Huge Thick Conglomerate}

(1) The Result from Surface Subsidence. It can be seen from Figure 8 that all the points of the strike line on the surface are obviously uplifted before April 2019. In June 2019, the 53\# point slightly rose by $3 \mathrm{~mm}$, and many other points still show "flat" characteristics (no obvious subsidence) compared with the previous monitoring. For example, the 50\# and 52\# points only decrease by $4 \mathrm{~mm}$ and $7 \mathrm{~mm}$, respectively. After July 2019, all the points subside. Therefore, the critical time of comovement disturbance is estimated to be June 2019 according to the surface subsidence.

(2) The Result from Microseismic Height. From the monthly average height of microseismic events in 13230 face (Figure 9), the microseismic height has a sudden rise in many periods in the years of 2015 to 2018 . In the year of 2019, the height increases from $5.89 \mathrm{~m}$ to $12.17 \mathrm{~m}$ from January to July, and then it decreases to less than $5 \mathrm{~m}$ and fluctuates within $\pm 3 \mathrm{~m}$. Therefore, the critical time of comovement 

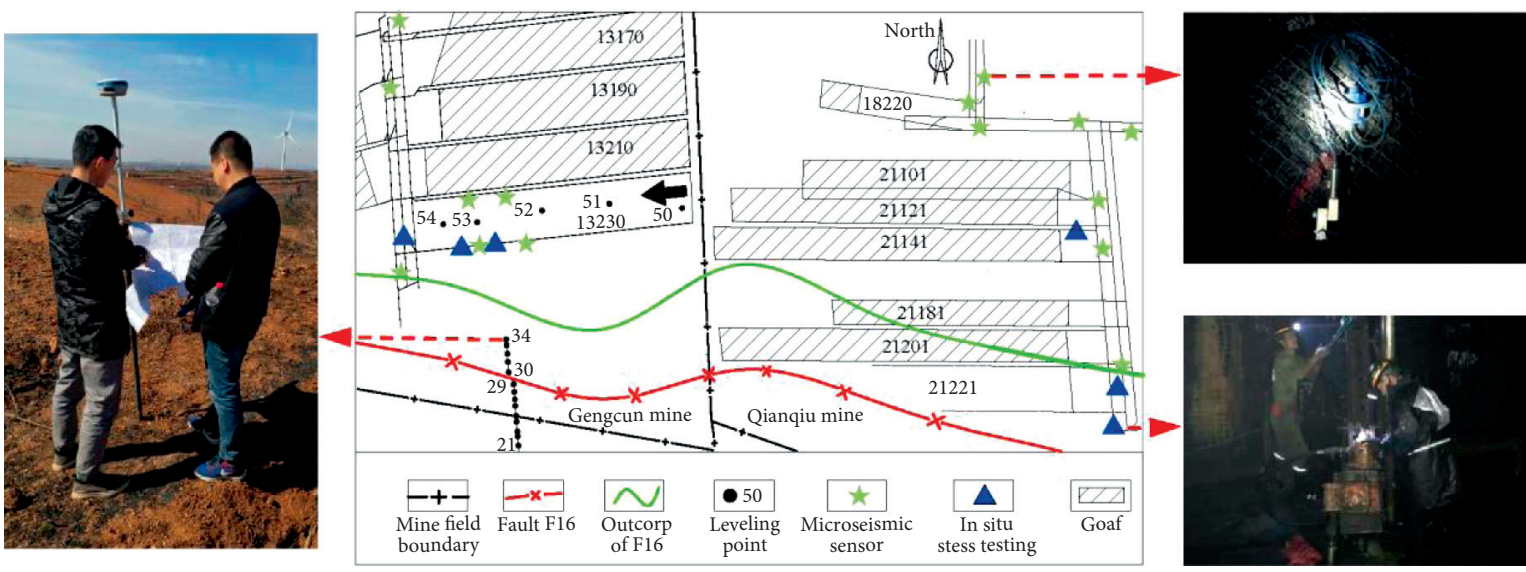

FIGURE 7: The distribution of working face and integrated-united monitoring in the Gengcun-Qianqiu area.

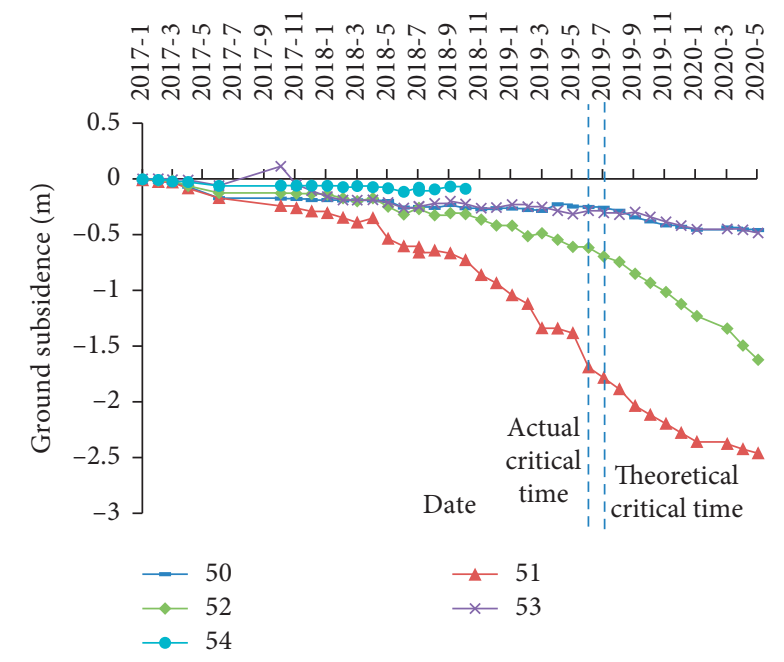

FIGURE 8: The surface subsidence along strike of 13230 face. [23].

disturbance is estimated to be July 2019 according to the microseismic height.

(3) The Result from Theoretical Calculation. In this area, the width of the coal pillar $(J)$ is $160 \mathrm{~m}$. The distance between the conglomerate beam and the coal seam $(h)$ is $358.66 \mathrm{~m}$. The caving angle $(\alpha)$ is $65^{\circ}$. The mining length $(m)$ of 21121 face is $1220 \mathrm{~m}$. Taking the above parameters into equation (16), it can be concluded that the disturbed range of mining length for 13230 face is $0 \leq n \leq 653.7 \mathrm{~m}$. According to the actual mining progress, the cumulative mining length of 13230 face is $653.4 \mathrm{~m}$ on $2019-7-7$ and $654 \mathrm{~m}$ on $2019-7-8$, respectively. So it is considered that $2019-7-7$ is the critical time for the 13230 face disturbed by conglomerate.

In summary, the results show that the test values are basically consistent with the theoretical value, and the validity of the theory is further verified.

4.3. Activation Characteristics of Fault F16. During the mining period of 13230 working face, the subsidence characteristics of the points on dip orientation are shown in

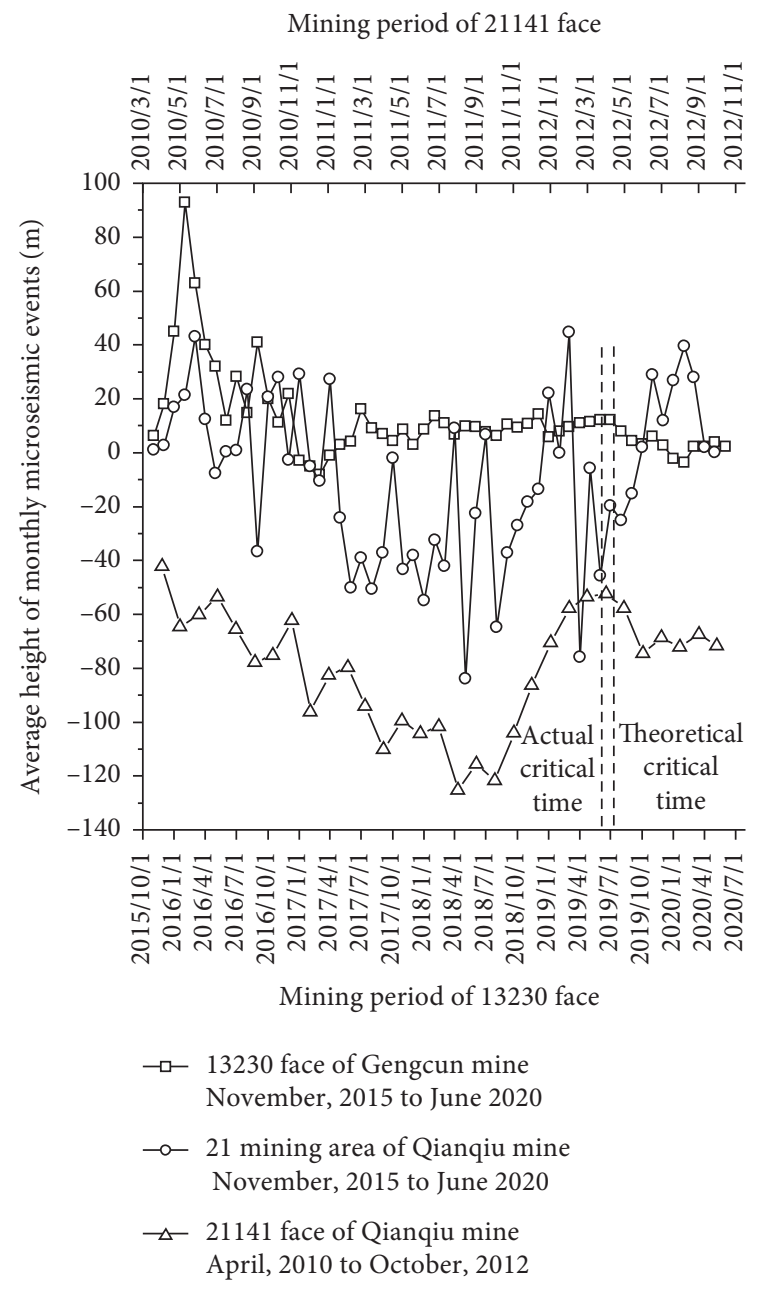

FIgURE 9: Height variation of microseismic events. [23].

Figure 10. It can be seen from Figure 10 that an obvious uplifting movement occurs at every point on the surface of fault's hanging wall. The closer the point is to the fault outcrops to the surface $(21 \# \sim 27 \#$ points), the higher the surface uplift is caused by fault slip. For example, the maximum uplifting of $21 \# \sim 27 \#$ points during the adjacent 


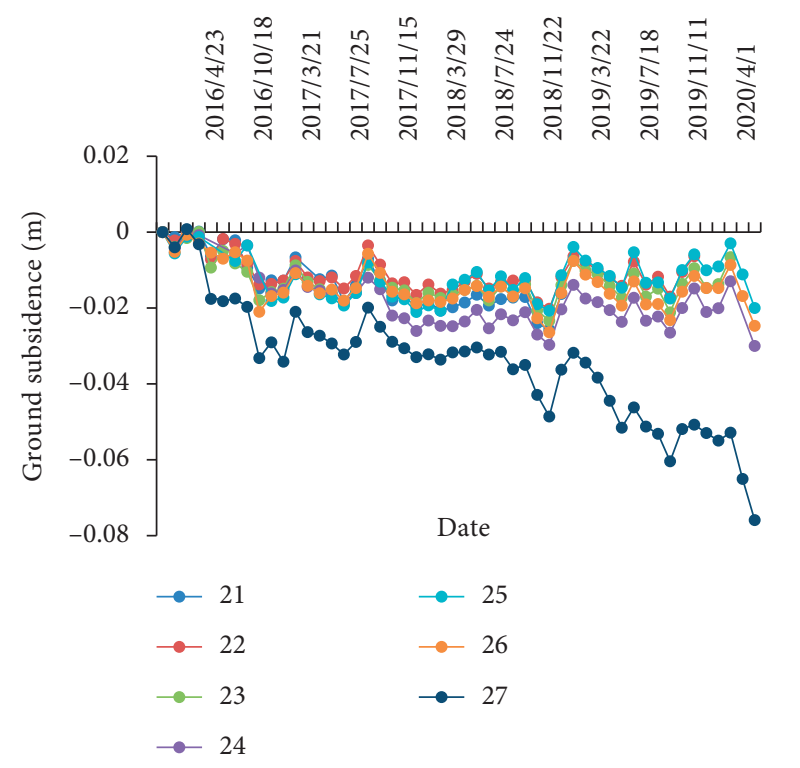

(a)

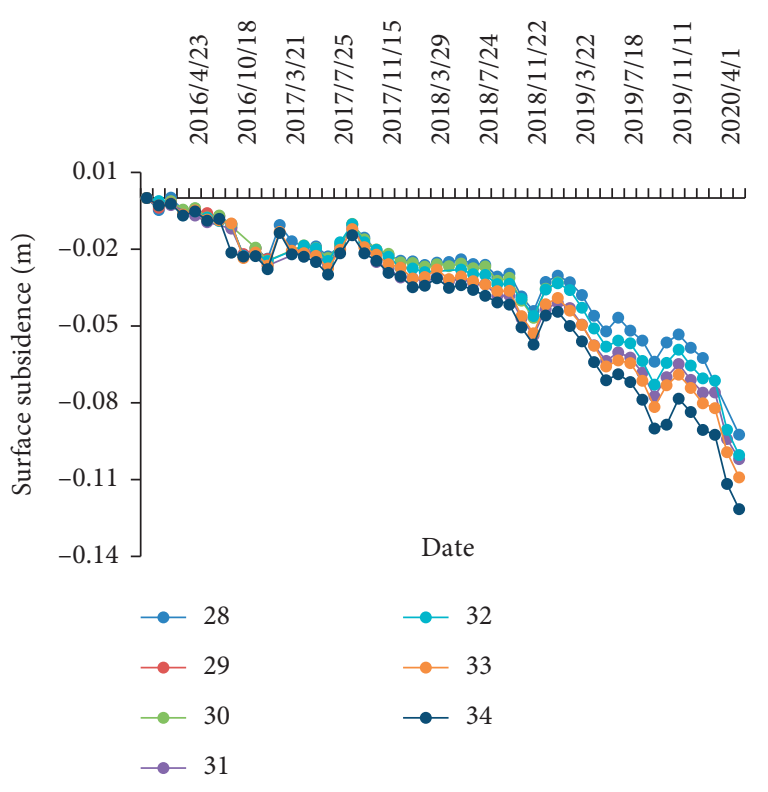

(b)

FIGURE 10: Surface observation of fault activation: (a) 21\# 27\# points and (b) $28 \# \sim 34 \#$ points.

monitoring period is $1.315 \mathrm{~cm}(2017-2-24)$, and the average uplift is $0.373 \mathrm{~cm}$, while the maximum uplift and average uplift of $28 \# \sim 34 \#$ points are $1.415 \mathrm{~cm}$ and $0.413 \mathrm{~cm}$, respectively, and the time when maximum uplifting occurred is also on 2017-2-24.

Therefore, the mining disturbance of 13230 face induces the gradual activation of fault F16 in the south of Gengcun 13 mining area. The compressive stress caused by compression in thrust nappe system is the key dynamic mechanism of coal bump.

\subsection{Mechanism of Coal Bump in the Later Face}

4.4.1. Evolution of Vertical Stress. The stress in this section is derived from monitoring data in Section 4.1.2.

In 13230 working face, the front pillar pressure of 27\# and 28\# substations located in the middle of the face is used to characterize the change of roof pressure during the mining process. However, the laws of pressure variation of other substations are similar, which is not given here due to space limitation. The variation of roof pressure is shown in Figure 11 [23].

Figure 11 shows that the roof pressure is low at beginning of the later face but gradually increases. For example, the peak pressure in the beginning and middle periods and the fitting line in the whole period all show a gradual upward trend.

It is the rising of the conglomerate above later face induced by that above former face that the effect of vertical pressure in 13230 face is weakened.

4.4.2. Characteristics of Coal Bump Behavior in the Later Face. There are many kinds of phenomena for coal bumps during the mining of 13230 face, including coal sliding in

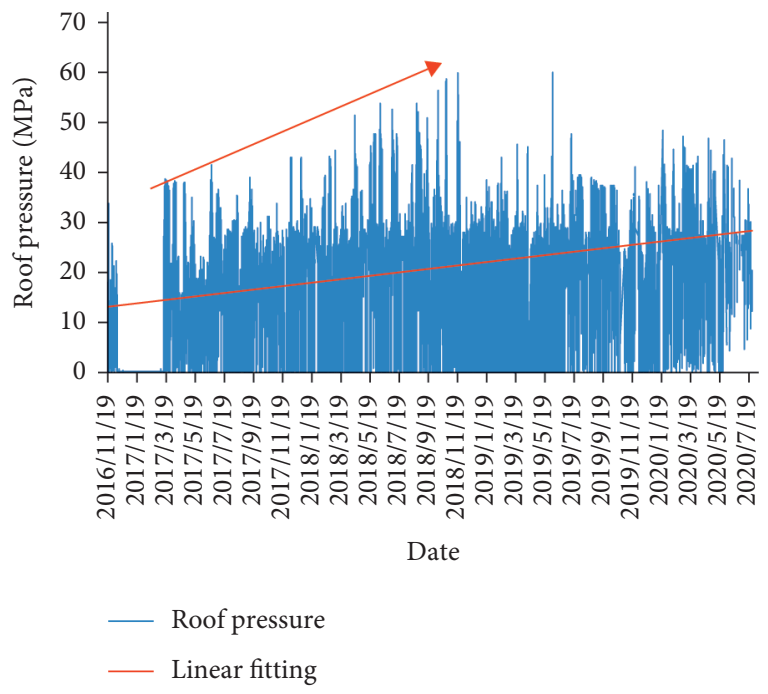

FIGURE 11: Variation of roof pressure in 13230 face [23].

roadway, floor heave, sliding and sinking or damage of support equipment, shifting of equipment displacement, vibration, noise, coal dust dispersion, coal falling on floor, and stress rising in borehole. According to the direction of coal bump behavior, Table 1 summarizes the horizontal and vertical behaviors in different mining periods. In addition, the coal bump behavior is nonobvious direction during 2019-07-23 2020-06-17, in which the behaviors are not classified.

According to common-sense cognition, to some extent, the coal bump behaviors in horizontal or vertical direction are related to the stress in corresponding direction. Therefore, it is considered that the sliding of coal and supporting equipment is mainly caused by horizontal stress, 
TABLE 1: The coal bump behavior in 13230's mining process.

\begin{tabular}{lcc}
\hline Date & Horizontal direction & Description of coal bump characteristics \\
Vertical direction
\end{tabular}

and increasing vertical stress of borehole and supporting equipment is mainly caused by vertical stress.

Table 1 shows that, during the mining process of 13230 , the uplifting and pressure relief by comovement of huge thick conglomerate in the initial mining stage weaken the longitudinal constraint of coal body, resulting in longer sliding of coal body or support equipment. In the later mining stage, the balance of structure gradually reduces the horizontal sliding and gradually leads to severer behavior in the vertical direction-the coal bump phenomena develop from small increase or even decrease of vertical stress in individual borehole to high increase of stress in multiple boreholes and supports. In addition, the sliding phenomena occur before 2019-07-09 but disappear after that.

Therefore, it is considered that the critical time between the existence and nonexistence of comovement uplift effect at initial or later mining stage is 2019-07-09, which is basically consistent with the theoretical time (2019-07-07).

\subsubsection{The Explaining of Coal Bump Induced by Conglomerate's} Comovement. According to test results of the in situ stress (Figure 7), the maximum horizontal principal stress and vertical stress of the three points in 13230 face are $13.83 \mathrm{MPa}$ and $15.55 \mathrm{MPa}, 12.58 \mathrm{MPa}$ and $15.53 \mathrm{MPa}, 14.84 \mathrm{MPa}$ and $14.98 \mathrm{MPa}$, respectively [23]. In addition, the maximum horizontal principal stress and vertical stress of the three points in Qianqiu 21 mining area are $17.51 \mathrm{MPa}$ and 15.83 MPa, $18.01 \mathrm{MPa}$ and $18.23 \mathrm{MPa}, \quad 22.87 \mathrm{MPa}$ and $19.54 \mathrm{MPa}$, respectively [23].

According to the stress value only, the horizontal stress of 13230 face is slightly lower than the vertical stress, and the horizontal stress of Qianqiu 21 mining area is obviously higher than the vertical stress. According to the 4108\# geological borehole in the area, the immediate roof and immediate floor of the coal seam are mudstone, and there is a $38 \mathrm{~cm}$ thin layer of carbonaceous mudstone. The friction coefficient of coal and mudstone is $0.61-0.63$ and $0.61-0.65$, respectively, from mechanical test of coal-rock sliding $[25,26]$. Therefore, the average value of friction coefficient is 0.63 . It is obvious that the horizontal stress of coal in the area is obviously higher than the limit of friction. At the same time, the horizontal stress is further increased with the fault slip caused by mining. In summary, the high horizontal stress caused by thrust movement of F16 leads to the natural easy-sliding environment for coal mass.

When there is no mining activity, the original vertical stress, the original horizontal stress, and the attribute of coalrock joints have reasonable matching relationship, so stress state in the coal and rock mass is balanced. When there exist close-range faces, the vertical stress of coal-rock mass in later face is reduced due to the comovement of thick rock strata, which weakens the longitudinal restraint effect for coal mass. At this time, if the horizontal stress exceeds the friction limit, the coal bump with horizontal sliding of coal mass may be induced. With increasing mining length of the later face, the structure of higher overlying strata gradually tends to be "balanced." This process eventually leads to the gradual increase of vertical stress, which gradually weakens the coal bump in horizontal direction and enhances that in vertical direction. Therefore, the comovement effect of higher strata changes the stress proportion on coal mass in vertical direction, which leads to different directions of coal bumps.

\section{Discussion}

The phenomenon of slight lifting of thick conglomerate in a short time is directly verified by the surface uplift movement of adjacent monitoring. The most direct influence of conglomerate's uplift on coal and rock mass is the change of vertical stress environment of coal body, and the vertical stress environment is the key factor restricting the horizontal 
slip of coal body. During the time when the thick conglomerate shows comovement effect, the horizontal bump of the coal body is easy to occur, and the hydraulic props slides in in the horizontal direction under the influence of coal sliding.

Furthermore, the typical periods of surface uplift are 2017-10-01, 2018-03-01, 2018-04-01, 2018-07-01, and 2019-06-01 (Figure 8). According to Table 1, except for 2019-06-01, there are coal bumps before the surface uplift within one month. Except for July 1, 2018, the working face shows coal bump behaviors after the surface uplift within one month. The relationship between the coal bump and conglomerate uplift in the later face further inferred that the coal bump induces the uplift of conglomerate, which further induces the future bump.

In the paper, the observations are only arranged in underground mine and the surface, and the displacement measuring points are not arranged in the different depths in the surface boreholes, so it is impossible to get the difference of uplift characteristics in different height of $290 \mathrm{~m}$ thick conglomerate. Thus, the integrated monitoring in the full space with "underground-ground-sky" will be carried out in the future.

\section{Conclusion}

(1) Under the condition of large-scale mining in Yima coalfield, the structural unit is composed of two goafs, intermediate coal pillar and overlying conglomerate. The huge thick conglomerate is characterized by low-level falling and high-level hanging, which provides physical factor for the disaster caused by large-scale movement of strata.

(2) In the structural unit of Yima coalfield, the subsidence of huge thick conglomerate in the former face will induce the uplift of that in the later face. The uplift is a state with high position in theory and upward movement during the adjacent observation period in actual test, which is called comovement effect of huge thick conglomerate.

(3) When the huge thick conglomerate uprises, the mining length of the later face follows the equation $n \leq m / 2-J / 4+h \cot \alpha / 2$. In this range, the uplift leads to low vertical stress for the later face in the initial stage, and the high horizontal stress caused by thrust movement of fault F16 induces coal bump with characteristic of horizontal sliding. However, the horizontal-sliding coal bump will not occur any more when out of the range.

(4) The comovement effect of higher strata changes the stress proportion on coal mass in vertical direction, which leads to different directions of coal bump. The intensity and frequency of coal bump in horizontal direction are higher during the initial stage of 13230; with the increasing mining length of 13230 , the bump effect in horizontal direction is gradually weakened, while that in the vertical direction is gradually strengthened.

\section{Data Availability}

The data used to support the findings of this study are available from the first author upon request.

\section{Conflicts of Interest}

The authors declare that they have no conflicts of interest.

\section{Acknowledgments}

This work was financially supported by the National Key Research and Development Program of China (Nos. 2017YFC0804203 and 2017YFC0804201) and the National Natural Science Foundation of China (No. 51874176).

\section{References}

[1] C. Mark, "Coal bursts in the deep longwall mines of the United States," International Journal of Coal Science \& Technology, vol. 3, no. 1, pp. 1-9, 2016.

[2] A. T. Iannacchione and S. C. Tadolini, "Occurrence, predication, and control of coal burst events in the U.S," International Journal of Mining Science and Technology, vol. 26, no. 1, pp. 39-46, 2016.

[3] L.-M. Dou, X.-Q. He, H. He, J. He, and J. Fan, "Spatial structure evolution of overlying strata and inducing mechanism of rockburst in coal mine," Transactions of Nonferrous Metals Society of China, vol. 24, no. 4, pp. 1255-1261, 2014.

[4] R. Singh, P. K. Mandal, A. K. Singh, R. Kumar, J. Maiti, and A. K. Ghosh, "Upshot of strata movement during underground mining of a thick coal seam below hilly terrain," International Journal of Rock Mechanics and Mining Sciences, vol. 45, no. 1, pp. 29-46, 2008.

[5] R. Singh, P. K. Mandal, and A. K. Singh, "Rakesh Kumar and Amalendu Sinha. Coal pillar extraction at deep cover: with special reference to Indian coalfields," International Journal of Coal Geology, vol. 86, no. 2, pp. 276-288, 2011.

[6] P. K. Mandal, R. Singh, J. Maiti, A. K. Singh, R. Kumar, and A. Sinha., "Underpinning-based simultaneous extraction of contiguous sections of a thick coal seam under weak and laminated parting," International Journal of Rock Mechanics and Mining Sciences, vol. 45, no. 1, pp. 11-28, 2008.

[7] A. T. Iannacchione, P. R. Coyle, L. J. Prosser, T. E. Marshall, and J. Litsenberger, "The relationship of roof movement and strata-induced microseismic emissions to roof falls," in Proceedings of the SME Annual Meeting, pp. 1-9, Denver, CO, USA, February 2004.

[8] B. Unver and N. E. Yasitli, "Modelling of strata movement with a special reference to caving mechanism in thick seam coal mining," International Journal of Coal Geology, vol. 66, no. 4, pp. 227-252, 2006.

[9] H. Alehossein and B. A. Poulsen, "Stress analysis of longwall top coal caving," International Journal of Rock Mechanics and Mining Sciences, vol. 47, no. 1, pp. 30-41, 2010.

[10] R. Gao, B. Yu, H. Xia, and H. Duan, "Reduction of stress acting on a thick, deep coal seam by protective-seam mining," Energies, vol. 10, no. 8, p. 1209, 2017.

[11] R. Gao, B. Yu, and X. Meng, "Stress distribution and surrounding rock control of mining near to the overlying coal pillar in the working face," International Journal of Mining Science and Technology, vol. 29, no. 6, pp. 881-887, 2019. 
[12] B. Yu, J. Zhao, T. Kuang, and X. Meng, "In situ investigations into overburden failures of a super-thick coal seam for longwall top coal caving," International Journal of Rock Mechanics and Mining Sciences, vol. 78, pp. 155-162, 2015.

[13] L. Driad-Lebeau, F. Lahaie, and M. A. Heib, "Seismic and geotechnical investigations following a rockburst in a complex French mining district," International Journal of Coal Geology, vol. 64, no. 1/2, pp. 66-78, 2005.

[14] S. Salimzadeh, A. Paluszny, T. Usui, A. Paluszny, and R. W. Zimmerman, "Finite element simulations of interactions between multiple hydraulic fractures in a poroelastic rock," International Journal of Rock Mechanics and Mining Sciences, vol. 99, pp. 9-20, 2017.

[15] C. Liu, H. Li, H. Mitri, D. Jiang, H. Li, and J. Feng, "Voussoir beam model for lower strong roof strata movement in longwall mining_case study," Journal of Rock Mechanics and Geotechnical Engineering, vol. 9, no. 6, pp. 1171-1176, 2017.

[16] G. S. P. Singh and U. K. Singh, "Prediction of caving behavior of strata and optimum rating of hydraulic powered support for longwall workings," International Journal of Rock Mechanics and Mining Sciences, vol. 47, no. 1, pp. 1-16, 2010.

[17] S. He, D. Song, X. He et al., "Coupled mechanism of compression and prying-induced rock burst in steeply inclined coal seams and principles for its prevention," Tunnelling and Underground Space Technology, vol. 98, pp. 1-22, 2020.

[18] B. J. Andrews, Z. A. Cumberpatch, Z. K. Shipton, and R. Lord, "Collapse processes in abandoned pillar and stall coal mines: implications for shallow mine geothermal energy," Geothermics, vol. 88, pp. 1-14, 2020.

[19] D. Mondal, P. N. S. Roy, and P. K. Behera, "Use of correlation fractal dimension signatures for understanding the overlying strata dynamics in longwall coal mines," International Journal of Rock Mechanics and Mining Sciences, vol. 91, pp. 210-221, 2017.

[20] C. Wu, L. Dou, G. Si, and Y. Hu, "Fault-induced coal burst mechanism under mining-induced static and dynamic stresses," Engineering, vol. 2, pp. 1-24, 2020.

[21] P. R. Fernández, G. R. Granda, A. Krzemień, S. G. Cortés, and G. F. Valverde, "Subsidence versus natural landslides when dealing with property damage liabilities in underground coal mines," International Journal of Rock Mechanics and Mining Sciences, vol. 126, pp. 1-13, 2020.

[22] M. Eremin, G. Esterhuizen, and I. Smolin, "Numerical simulation of roof cavings in several Kuzbass mines using finitedifference continuum damage mechanics approach," International Journal of Mining Science and Technology, vol. 30, no. 2, pp. 157-166, 2020.

[23] Y. Li, S. Zhao, Q. Qi et al., "Preliminary study on coal bump mechanism induced by co-movement of higher strata and coal bump control method between two mines," Journal of China Coal Society, vol. 45, no. 5, pp. 1681-1690, 2020.

[24] M. G. James and J. G. Barry, Strength of Materials, China Machine Press, Beijing, China, 2011.

[25] W. Han, "The study of frictional sliding characters of rocks and its influencing factors," Ph. D thesis, Tai Yuan University of Technology, Taiyuan, China, 2012.

[26] C. He, B. A. Verberne, and C. J. Spiers, "Frictional properties of sedimentary rocks and natural fault gouge from Longmenshan fault zone and their implications," Chinese Journal of Rock Mechanics and Engineering, vol. 30, no. 1, pp. 113-131, 2011. 